\title{
The chain of survival in hypothermic circulatory arrest: encouraging preliminary results when using early identification, risk stratification and extracorporeal rewarming
}

Tomasz Darocha ${ }^{1,2^{*}}$, Sylweriusz Kosiński ${ }^{3,4}$, Anna Jarosz ${ }^{1}$, Dorota Sobczyk ${ }^{5}$, Robert Gałązkowski ${ }^{2,6}$, Jacek Piątek Janusz Konstany-Kalandyk ${ }^{7}$ and Rafał Drwiła ${ }^{1}$

\begin{abstract}
Background: The prognosis in hypothermic cardiac arrest is frequently good despite prolonged period of hypoperfusion and cardiopulmonary resuscitation. Apart from protective effect of hypothermia itself established protocols of treatment and novel rewarming techniques may influence on outcome.

The purpose of the study was to assess the outcome of patients with hypothermic circulatory arrest treated by means of arterio-venous extracorporeal membrane oxygenation (ECMO) according to locally elaborated protocol in Severe Accidental Hypothermia Center in Cracow, Poland.

Methods: Prospective observational case-series study - all patients with confirmed hypothermic cardiac arrest consulted with hypothermia coordinator were accepted for extracorporeal rewarming, unless contraindications for ECMO were observed (active bleeding).

Results: The study population consisted of 10 patients ( 7 male, median age 48.5 years). The core temperature measured esophageally was $16.9-28.4^{\circ} \mathrm{C}$, median $22^{\circ} \mathrm{C}$. On admission 5 patients presented with asystole and 5 with ventricular fibrillation. Duration of circulatory arrest before ECMO implantation was 107 to 345 min (median $156 \mathrm{~min}$ ). The duration of ECMO support was 1.5 to $91 \mathrm{~h}$ (median $22 \mathrm{~h}$ ). Cardiorespiratory stability and full neurologic recovery was achieved in 7 patients. The duration of mechanical ventilation was 88-437 h (median $177 \mathrm{~h}$ ) and the length of stay in the ICU was 8-26 days (median 15 days). All survivors had mildly impaired (1 patient, LVEF $40 \%$ ) or preserved (6 patients, LVEF 55-65\%) left ventricular systolic function at the time of discharge from ICU. The cause of death of non-survivors (three patients) was acute myocarditis, massive retroperitoneal bleeding, and massive gastrointestinal bleeding.

Discussion and Conclusions: Our data confirm the high survival rate (70 \%) and excellent neurologic outcome in hypothermic cardiac arrest. The following key elements seem to impact the final prognosis: the appropriate coordination of the rescue operation, immediate high-quality CPR (preferably using mechanical chest compression system) and application of ECMO for rewarming and cardiorespiratory support.
\end{abstract}

Keywords: Accidental hypothermia, Cardiac arrest, Cardiopulmonary resuscitation, Extracorporeal membrane oxygenation

\footnotetext{
* Correspondence: tomekdarocha@wp.pl

${ }^{1}$ Department of Anesthesiology and Intensive Care, the John Paul II Hospital,

Medical College of Jagiellonian University, Cracow, Poland

${ }^{2}$ Polish Medical Air Rescue, Warsaw, Poland

Full list of author information is available at the end of the article
} 


\section{Background}

Accidental hypothermia is defined as an involuntary drop in core temperature below $35^{\circ} \mathrm{C}$. Recent guidelines recommend a standard classification of hypothermia based on a core temperature and vital signs (Swiss staging system). Severe hypothermia (core temperature of less than $28{ }^{\circ} \mathrm{C}$ ) is associated with a high risk of circulatory arrest and high mortality (due to progressive systemic edema, respiratory insufficiency and neurologic complications) [1].

Currently, several non-invasive and invasive methods of rewarming are being used [1]. Successful management of severe accidental hypothermia has been achieved using invasive rewarming techniques in selected victims. Early rewarming with extracorporeal membrane oxygenation (ECMO) is recommended by the European Resuscitation Council as the method of choice in rewarming from severe accidental hypothermia with cardiac instability or circulatory arrest [2]. ECMO allows rapid and safe rewarming, enables continuous oxygenation and hemodynamic support. It decreases the incidence of severe cardiorespiratory instability that often complicates restoring normal body temperature [3].

In the years 2009-2013 the Polish National Statistics Department reported 2198 deaths due to exposure to excessive natural cold [4]. 624 of these patients $(28.39 \%)$ died in hospital. The introduction of innovative system for identification of hypothermic patients and early qualification for the extracorporeal rewarming may reduce the number of potentially preventable deaths. In July 2013 the Severe Accidental Hypothermia Center (SAHC) was founded in the John Paul II Hospital in Cracow [5]. It is a unit functioning within the structure of the Cardiac Surgery Clinic established in order to improve the effectiveness of the treatment of patients in severe hypothermia from the Lesser Poland (Małopolska) province (area of 15100 square $\mathrm{km}$, population of 3.3 million)

\section{Study objective}

The purpose of the present study was to assess the outcome of patients with hypothermic circulatory arrest treated by means of arterio-venous extracorporeal membrane oxygenation (ECMO).

\section{Methods}

The prospective observational case-series study was approved by the Local Ethical Committee of the John Paul II Hospital in Cracow. After full recovery, all the study subjects gave informed consent to the use of their medical data.

From 29 July 2013 to 29 November 2015, we consulted 137 hypothermic patients. 115 patients in the II and III stages of severe hypothermia (according to the
Swiss scale i.e., stable circulation and respiration) were rewarmed using conventional methods and 22 patients were accepted for extracorporeal rewarming. 10 patients with cardiac arrest and 12 with severe cardiogenic shock and core temperature below $28 \mathrm{C}$ were enrolled for veno arterial ECMO treatment.

All ten patients who were admitted to the Severe Accidental Hypothermia Center in hypothermic cardiac arrest were enrolled in the study. All of them fulfilled the established criteria and undergone rewarming with ECMO in arterio-venous configuration (Maquet Rotaflow). Surgical cannulation of femoral vessels was performed, preferably unilateral. Continuous unfractionated heparin infusion was administered to provide adequate level of anticoagulation, with ACT times being in the range of 140-160 s.

Blood samples were collected for the arterial gases, blood glucose and chemistry analysis at the time of admission and immediately after rewarming. Blood tests were assayed by routine automated laboratory techniques (Cobas System 600, Roche Diagnostics GmbH, Manheim, Germany). All biochemical analyses were performed in the central hospital laboratory, certified with a cardiac and clinical chemistry program by RIQAS (Randox Quality Assessment Scheme, UK). Transthoracic echocardiography was performed on discharge from the Intensive Care Unit (ICU) after achieving cardiovascular stability. The examinations were conducted by means of a portable ultrasound system equipped with a 1-5 MHz transthoracic phased-array transducer (CX 50, Philips, Eindhoven, Netherlands).

Since restoration of hemodynamic stability was the priority of extracorporeal rewarming, the targeted temperature was $36,6{ }^{\circ} \mathrm{C}$ - no post-cardiac arrest therapeutic hypothermia was maintained.

\section{Results}

The study population consisted of 10 patients ( 7 male, age 25-78 years, median age 48.5 years), transported by ambulance ( 6 patients) or by helicopter (4 patients) from the distance 1-128 km (median $85.5 \mathrm{~km}$ ). They were admitted in circulatory arrest secondary to hypothermia (core temperature measured esophageally $16.9-28.4{ }^{\circ} \mathrm{C}$, median $22^{\circ} \mathrm{C}$ ). Demographic and admission clinical data are presented in Table 1. Five patients (50 \%) were reported by the emergency medical services and were transported directly to Severe Accidental Hypothermia Center. The other five patients were transferred via regional emergency departments. It should be noticed, that at least three patients deteriorated rapidly during initial treatment (triage, examination or decontamination). On admission to SAHC 5 patients presented with asystole and 5 with ventricular fibrillation. Duration of circulatory arrest before ECMO implantation was 107 to $345 \mathrm{~min}$ (median $156 \mathrm{~min}$ ). The duration of ECMO support was 1.5 to $91 \mathrm{~h}$ (median $22 \mathrm{~h}$ ) (Table 2). 
Table 1 Demographic and clinical characteristics of the study population on admission

\begin{tabular}{|c|c|c|c|c|c|c|}
\hline $\mathrm{Nr}$ & Sex/age (yrs) & Type of accident & Transportation distance $(\mathrm{km})$ & Type of transportation & Admission ECG & Core esophageal temperature $\left({ }^{\circ} \mathrm{C}\right)$ \\
\hline 1 & $M / 29$ & Alpine & 98 & Abmulance & Asystole & 22.3 \\
\hline 2 & $M / 52$ & Urban & 1 & Ambulance & VF & 22.2 \\
\hline 3 & $M / 78$ & Urban & 73 & Ambulance & VF & 24 \\
\hline 4 & $M / 55$ & Urban & 47 & Ambulance & Asystole & 24.1 \\
\hline 5 & $F / 25$ & Alpine (avalanche) & 128 & Helicopter & VF & 16.9 \\
\hline 6 & $M / 68$ & Urban & 102 & Helicopter & VF & 24 \\
\hline 7 & $F / 38$ & Urban & 5 & Ambulance & VF & 25.4 \\
\hline 8 & $M / 45$ & Urban & 114 & Helicopter & Asystole & 22 \\
\hline 9 & M54 & Urban & 102 & Helicopter & Asystole & 25.9 \\
\hline 10 & $F / 28$ & Diving & 9 & Ambulance & Asystole & 28.4 \\
\hline
\end{tabular}

Analysis of arterial blood samples collected on admission revealed metabolic acidosis $(\mathrm{pH}$ 6.56-7.14, bicarbonate level $5.6-17.3 \mathrm{mmol} / \mathrm{l}$ ) and elevated lactate levels (7.1-17 $\mathrm{mmol} / \mathrm{l})$ in all patients. Blood glucose analysis showed hyperglycemia (median $12 \mathrm{mmol} /$ ) in 7 patients, 2 patients were hypoglycemic $(2.6 \mathrm{mmol} / \mathrm{l}$ and $2.8 \mathrm{mmol} / \mathrm{l})$. Two patients were hypokalemic, 1 patient presented with hyperkalemia of $6.4 \mathrm{mmol} / \mathrm{l}$, (Table 3). Arterial blood gases, blood glucose and chemistry results immediately after ECMO rewarming are summarized in Table 4.

One patient (a 28-year-old female, injured while diving) died in the operating theatre, $1.5 \mathrm{~h}$ after ECMO implantation. Autopsy revealed active myocarditis. The other two patients died in the intensive care unit several hours after ECMO implantation. One of them died due to massive retroperitoneal bleeding, in a second one autopsy showed massive gastrointestinal bleeding.

Cardiorespiratory stability and full neurologic recovery was achieved in 7 patients (Cerebral Performance Category 1). The duration of mechanical ventilation was 88-437 h (median $177 \mathrm{~h}$ ) and the length of stay in the ICU was 8-26 days (median 15 days). All survivors had mildly impaired (1 patient, LVEF $40 \%$ ) or preserved (6 patients, LVEF 55-65 \%) left ventricular systolic function at the time of discharge from ICU (Table 2).

\section{Discussion}

Severe accidental hypothermia is a rare condition associated with significant morbidity and mortality [1]. Severe Accidental Hypothermia Center provides $24 \mathrm{~h}$ on-call consultation and qualification for extracorporeal rewarming. A trilateral phone calls between the dispatch center, on-site emergency medical team and the hypothermia coordinator are possible enabling immediate decision making. A crucial issue is precise coordination of rescue achieved with localization system and close cooperation with Dispatch Centre. Planning and proceeding in accordance with guidelines and dedicated protocols, enables shortening the transport time and implementing an effective treatment. In our study group, there were seven patients transported from a long distance $(47-128 \mathrm{~km})$ - four patients by helicopter and three by ambulance.

Table 2 Hemodynamic data and clinical outcome of the study population

\begin{tabular}{|c|c|c|c|c|c|c|c|c|}
\hline $\mathrm{Nr}$ & $\begin{array}{l}\text { Duration of cardiac } \\
\text { arrest before ECM } \\
\text { implantation (min) }\end{array}$ & $\begin{array}{l}\text { Rewarming } \\
\text { rate }(C / h)\end{array}$ & $\begin{array}{l}\text { Duration of ECMO } \\
\text { rewarming }(h)\end{array}$ & $\begin{array}{l}\text { Mechanical } \\
\text { ventilation (h) }\end{array}$ & $\begin{array}{l}\text { Duration of ICU } \\
\text { stay (days) }\end{array}$ & Outcome & $\begin{array}{l}\text { Discharge } \\
\text { LVEF (\%) }\end{array}$ & $\begin{array}{l}\text { Clinical status at } \\
\text { discharge from ICU }\end{array}$ \\
\hline 1 & 150 & 1.6 & 32 & 94 & 8 & Fully recovered & 65 & GCS 15, CPC 1 \\
\hline 2 & 140 & 4.0 & 22 & 88 & 11 & Fully recovered & 40 & GCS 15, CPC 1 \\
\hline 3 & 144 & 2.0 & 27 & 313 & 22 & Fully recovered & 60 & GCS 15, CPC 1 \\
\hline 4 & 155 & 0.5 & 23 & 319 & 15 & Fully recocvered & 55 & GCS 15, CPC 1 \\
\hline 5 & 345 & 4.5 & 91 & 134 & 26 & Fully Recovered & 60 & GCS 15, CPC 1 \\
\hline 6 & 177 & 2.0 & 8 & 177 & 12 & Fully recovered & 60 & GCS 15, CPC 1 \\
\hline 7 & 107 & 1.5 & 22 & 437 & 21 & Fully recovered & 60 & GCS 15, CPC 1 \\
\hline 8 & 280 & 3 & 5 & 5 & 1 & Died & N/A & N/A \\
\hline 9 & 250 & 1.25 & 9 & 9 & 1 & Died & N/A & N/A \\
\hline 10 & 157 & 4.0 & 1.5 & 1.5 & 0 & Died & N/A & N/A \\
\hline
\end{tabular}


Table 3 Arterial blood gases, chemistry and blood glucose level in the study population on admission

\begin{tabular}{ccccccccccc}
\hline $\mathrm{Nr}$ & $\mathrm{pH}$ & $\begin{array}{l}\mathrm{pCO}_{2} \\
(\mathrm{mmHg})\end{array}$ & $\begin{array}{l}\mathrm{pO}_{2} \\
(\mathrm{mmHg})\end{array}$ & $\begin{array}{l}\mathrm{BE} \\
(\mathrm{mmol} / \mathrm{l})\end{array}$ & $\begin{array}{l}\mathrm{K} \\
(\mathrm{mmol} / \mathrm{l})\end{array}$ & $\begin{array}{l}\mathrm{Na} \\
(\mathrm{mmol} / \mathrm{l})\end{array}$ & $\begin{array}{l}\text { Lactates } \\
(\mathrm{mmol} / \mathrm{l})\end{array}$ & $\begin{array}{l}\mathrm{HCO}_{3} \\
(\mathrm{mmol} / \mathrm{l})\end{array}$ & $\begin{array}{l}\mathrm{Glucose} \\
(\mathrm{mmol} / \mathrm{l})\end{array}$ & $\begin{array}{l}\mathrm{Hemoglobin} \\
(\mathrm{g} / \mathrm{dl})\end{array}$ \\
\hline 1 & 6.91 & 75.8 & 49.4 & -20.8 & 4.6 & 141 & 13.5 & 14.4 & 2.8 & 14.5 \\
2 & 6.89 & 94.3 & 47.1 & -18.3 & 4.2 & 146 & 7.1 & 17.3 & 14.9 & 12.8 \\
3 & 6.78 & 64.6 & 85.8 & -24.7 & 3.6 & 142 & 12.8 & 9.1 & 2.6 & 8.9 \\
4 & 7.14 & 43.1 & 69.8 & -14.3 & 3.1 & 135 & 7.6 & 14.1 & 9.4 & 12.7 \\
5 & 6.64 & 79 & 92 & -33.2 & 4.3 & 139 & 17 & 7.9 & 9 & 14.3 \\
6 & 6.95 & 73.9 & 53.8 & -20.3 & 3.7 & 146 & 10.6 & 15.3 & 12 & 16.7 \\
7 & 6.94 & 43.3 & 138 & -22.2 & 2 & 128 & 12 & 8.9 & 28 & 9.6 \\
8 & 6.99 & 61.2 & 48.1 & -18.3 & 5 & 143 & 11,9 & 14.1 & 6.3 & 13.6 \\
9 & 6.67 & 57.4 & 48.8 & -31.2 & 4.4 & 152 & 16 & 7.6 & 7 & 15.6 \\
10 & 6.56 & 65.8 & 156 & -34.6 & 6.4 & 131 & 14 & 5.6 & 33 \\
\hline
\end{tabular}

Prognosis in hypothermic circulatory arrest is surprisingly good [3]. This is most probably associated with protecting effects of hypothermia itself. Even prolonged cardiac arrest and prolonged cardio-pulmonary resuscitation (CPR) do not usually cause hypoxic brain damage in severe hypothermia. There are several reports of full neurologic recovery of patients with hypothermic circulatory arrest [3]. According to the recent guidelines, in patients with severe hypothermia, CPR can be delayed and intermittent if it is not possible to perform continuous CPR (for example during difficult evacuations). However, it is postulated to minimize interruptions and apply mechanical chest compressions as soon as possible [6]. Mechanical compression has not been shown to have a survival advantage over manual compression, but the latter cannot be done effectively in a moving ambulance. Thus, the immediate provision of the device for mechanical chest compression is very important in carrying out the rescue operation. The Severe Accidental Hypothermia Center created a regularly updated map of such equipment in local emergency medicine system. In all patients in our study group, a high-quality CPR was initiated immediately (including endotrachaeal intubation, ventilation, infusion of inotropes/vasopressors) and performed continuously with short interruptions. In all 10 cases mechanical chest compression devices were used.
The survival rate in our study population was $70 \%$ that is consistent with the available reports. There must be highlighted that all survivors left ICU in excellent cardiovascular (LVEF 40-65 \%) and neurological status (CPC 1). We did not observe any complications associated with ECMO implantation or application (the longest duration of ECMO use was $91 \mathrm{~h}$ ). Wanscher et al. reported a $100 \%$ survival (with a full neurologic recovery in $85.7 \%$ of patients) in 7 victims of a boat accident with hypothermic cardiac arrest, treated with ECMO rewarming [7]. Ruttman et al. in the retrospective comparative study of 59 patients following hypothermic cardiac arrest noted a significant survival benefit with ECMO (75 vs $34 \%$ ) [8]. Mair et al. conducted a retrospective observational study of 22 patients following hypothermic cardiac arrest [9]. Overall survival was $45.5 \%$. Walpoth et al. showed a complete recovery in $93.3 \%$ of 15 long-term survivors of deep hypothermic cardiac arrest [10]. Eich et al. conducted a retrospective comparative study of 12 patients following drowning and hypothermic cardiac arrest treated with CBP (cardiopulmonary bypass). Survival was only $41,7 \%$ most probably due to asphyxia. Comparison between survivors and non-survivors revealed low submersion times, early initiation of basic life support, hypokalemia, female gender and slow rewarming to be significant prognostic indicators

Table 4 Arterial blood gases, chemistry and blood glucose level in the survivors immediately after ECMO rewarming

\begin{tabular}{ccccccccccc}
\hline $\mathrm{Nr}$ & $\mathrm{pH}$ & $\begin{array}{l}\mathrm{pCO}_{2} \\
(\mathrm{mmHg})\end{array}$ & $\begin{array}{l}\mathrm{pO}_{2} \\
(\mathrm{mmHg})\end{array}$ & $\begin{array}{l}\mathrm{BE} \\
(\mathrm{mmol} / \mathrm{l})\end{array}$ & $\begin{array}{l}\mathrm{K} \\
(\mathrm{mmol} / \mathrm{l})\end{array}$ & $\begin{array}{l}\mathrm{Na} \\
(\mathrm{mmol} / \mathrm{l})\end{array}$ & $\begin{array}{l}\text { Lactates } \\
(\mathrm{mmol} / \mathrm{l})\end{array}$ & $\begin{array}{l}\mathrm{HCO}_{3} \\
(\mathrm{mmol} / \mathrm{l})\end{array}$ & $\begin{array}{l}\mathrm{Glucose} \\
(\mathrm{mmol} / \mathrm{l})\end{array}$ & $\begin{array}{l}\mathrm{Hemoglobin} \\
(\mathrm{g} / \mathrm{dl})\end{array}$ \\
\hline 1 & 7.52 & 27.1 & 153 & -0.1 & 3 & 146 & 2.3 & 21.8 & 3.3 & 10.2 \\
2 & 7.25 & 30.2 & 142 & -13.1 & 3.7 & 147 & 8,7 & 12.7 & 6.6 & 9.1 \\
3 & 7.08 & 25.9 & 137 & -21.4 & 4 & 143 & 17 & 7.3 & 9.1 & 10.1 \\
4 & 7.31 & 41.1 & 79.1 & -3.3 & 4.7 & 136 & 1.8 & 21.6 & 9.1 & 9.1 \\
5 & 7.19 & 40.9 & 24,3 & -11.8 & 3.8 & 146 & 7.5 & 15 & 6.2 & 7.3 \\
6 & 7.17 & 28.5 & 162 & -17.5 & 3.6 & 150 & 14 & 9.9 & 8.6 & 12 \\
7 & 7.39 & 31.1 & 235 & -5.5 & 4.7 & 140 & 8.9 & 18.4 & 6.4 & 7.9 \\
\hline
\end{tabular}


of favorable outcomes [11]. Debaty et al. performed a retrospective cohort study on 48 patients with accidental hypothermia in French Alps over a 10-year period. Overall mortality was $50 \%$, and cardiac arrest related to rescue collapse was associated with favorable outcome [12].

\section{Conclusion}

Our data confirm the high survival rate $(70 \%)$ and excellent neurologic outcome after cardiac arrest secondary to severe accidental hypothermia. The following key elements seem to impact the final prognosis: the appropriate coordination of the rescue operation, immediate high-quality CPR (preferably using mechanical chest compression system) and application of ECMO for rewarming and cardiorespiratory support

\section{Abbreviations \\ CPB, cardio-pulmonary bypass; CPC, cerebral performance category; CPR, cardio-pulmonary resuscitation; ECMO, arterio-venous extracorporeal membrane oxygenation; ICU, intensive care unit; LVEF, left ventricular ejection fraction; SAHC, Severe Accidental Hypothermia Centre}

\section{Acknowledgments}

Written informed consent was obtained from the patients for publication of their individual details in this manuscript. The consent form is held by the authors and is available for review by the Editor-in-Chief.

\section{Authors' contributions}

TD: designed the study, supervised data collection, took part in manuscript preparation, contributed substantially to the revision of the manuscript, takes responsibility for the paper as a whole. SK: supervised data collection, contributed substantially to the revision of the manuscript. AJ, DS, RG: contributed substantially to the revision of the manuscript. JP, JKK, RD: provided advise on study design, contributed to the revision of the manuscript. All authors read and approved the final manuscript.

\section{Competing interest}

The authors declare that they have no competing interests.

\section{Financial support used for the study}

Publication was supported by the Faculty of Medicine of Jagiellonian University Medical College (Leading National Research Centre 2012-2017).

\section{Author details}

'Department of Anesthesiology and Intensive Care, the John Paul II Hospital, Medical College of Jagiellonian University, Cracow, Poland. ${ }^{2}$ Polish Medical Air Rescue, Warsaw, Poland. ${ }^{3}$ Department of Anesthesiology and Intensive Care, Pulmonary Hospital, Zakopane, Poland. ${ }^{4}$ Tatra Mountain Rescue Service, Zakopane, Poland. ${ }^{5}$ Department of Interventional Cardiology, the John Paul II Hospital, Cracow, Poland. ${ }^{6}$ Department of Emergency Medical Services, Medical University of Warsaw, Warsaw, Poland. 'Department of Cardiovascular Surgery and Transplantology, Collegium Medicum, Jagiellonian University, the John Paul II Hospital, Cracow, Poland.

Received: 8 March 2016 Accepted: 21 June 2016

Published online: 29 June 2016

\section{References}

1. Brown DJ, Brugger H, Boyd J, et al. Accidental hypothermia. N Engl J Med. 2012;367:1930-8.

2. Truhlár A, Deakinc CD, Soar J, et al. European Resuscitation Council Guidelines for Resuscitation 2015 Section 4. Cardiac arrest in special circumstances. Resuscitation. 2015:95:148-201.

3. Dunne $B$, Christou E, Duff $O$, et al. Extracorporeal-assisted rewarming in the management of accidental deep hypothermic cardiac arrest: a systematic review of the literature. Heart Lung Circ. 2014;23(11):1029-35.
4. Central Statistical Office of Poland. Demographic base. 2015.

5. Darocha T, Kosinski S, Jarosz A, et al. Severe Accidental Hypothermia Center. Eur J Emerg Med. 2015;22(4):288-91.

6. Gordon L, Paal P, Ellerton JA, et al. Delayed and intermittent CPR for severe accidental hypothermia. Resuscitation. 2015;90:46-9.

7. Wanscher M, Agersnap L, Ravn J, et al. Outcome of accidental hypothermia with or without circulatory arrest: experience from the Danish Præstø Fjord boating accident. Resuscitation. 2012;83(9):1078-84.

8. Rutmann E, Weissenbacher A, Ulmer $\mathrm{H}$, et al. Prolonged extracorporeal membrane oxygenation-assisted support provides improved survival in hypothermic patients with cardiocirculatory arrest. J Thorac Cardiovasc Surg. 2007;134(3):594-600

9. Mair $\mathrm{P}$, Kornberger $\mathrm{E}$, Furtwaengler $\mathrm{W}$, et al. Prognostic markers in patients with severe accidental hypothermia and cardiocirculatory arrest. Resuscitation. 1994:27:47-54.

10. Walpoth BH, Walpoth-Aslan BN, Mattle HP, et al. Outcome of survivors of accidental deep hypothermia and circulatory arrest treated with extracorporeal blood warming. New Engl J Med. 1997;337:1500-5.

11. Eich C, Bräuer A, Timmermann A, et al. Outcome of 12 drowned children with attempted resuscitation on cardiopulmonary bypass: an analysis of variables based on the "Utstein Style for Drowning". Resuscitation. 2007:75(1):42-52.

12. Debaty G, Moustapha I, Bouzat $P$, et al. Outcome after severe accidental hypothermia in the French Alps: a 10-year review. Resuscitation. 2015;93:118-23.
Submit your next manuscript to BioMed Central and we will help you at every step:

- We accept pre-submission inquiries

- Our selector tool helps you to find the most relevant journal

- We provide round the clock customer support

- Convenient online submission

- Thorough peer review

- Inclusion in PubMed and all major indexing services

- Maximum visibility for your research

Submit your manuscript at www.biomedcentral.com/submit 